\title{
Constructing stability landscapes to identify alternative states in coupled social-ecological agent-based models
}

\author{
Patrick Bitterman $^{1}$ and David A. Bennett ${ }^{1}$
}

\begin{abstract}
The resilience of a social-ecological system is measured by its ability to retain core functionality when subjected to perturbation. Resilience is contextually dependent on the state of system components, the complex interactions among these components, and the timing, location, and magnitude of perturbations. The stability landscape concept provides a useful framework for considering resilience within the specified context of a particular social-ecological system but has proven difficult to operationalize. This difficulty stems largely from the complex, multidimensional nature of the systems of interest and uncertainty in system response. Agent-based models are an effective methodology for understanding how cross-scale processes within and across social and ecological domains contribute to overall system resilience. We present the results of a stylized model of agricultural land use in a small watershed that is typical of the Midwestern United States. The spatially explicit model couples land use, biophysical models, and economic drivers with an agent-based model to explore the effects of perturbations and policy adaptations on system outcomes. By applying the coupled modeling approach within the resilience and stability landscape frameworks, we (1) estimate the sensitivity of the system to contextspecific perturbations, (2) determine potential outcomes of those perturbations, (3) identify possible alternative states within state space, (4) evaluate the resilience of system states, and (5) characterize changes in system-scale resilience brought on by changes in individual land use decisions.
\end{abstract}

Key Words: agent-based model; resilience; social-ecological system; stability landscape

\section{INTRODUCTION}

The current state of a social-ecological system (SES) is one realization of many possible outcomes. Each potential state has a set of characteristics (e.g., sustainability, resilience, performance metrics) related to its desirability to humans and its relationship with other systems. Systems can transition between states in response to internal processes, external perturbations, or purposeful adaptation. The resilience paradigm, a concept with academic roots reaching back decades (Holling 1973), is one way to conceptualize these state changes.

The trajectory of human development has long been considered unsustainable (Meadows et al. 1972, Kates et al. 2001), and the resilience of SESs remains an important and contemporary issue as societies are faced with increased uncertainty associated with the nature and magnitude of key system pressures (e.g., global climate change, resource scarcity, stagnant economic growth) (Gordon 2012). However, the task of modifying a system to become more resilient while balancing trade-offs among alternative goals (e.g., profitability, biodiversity) within a complex network of interacting processes represents a significant challenge (DeFries et al. 2004, Bennett et al. 2009, Carpenter et al. 2009). Further, although resilience is often considered a positive trait, attempts to increase resilience can also lock a system in an undesirable state (e.g., a poverty trap between resource exploitation and low income) (Allison and Hobbs 2004, Carpenter and Brock 2008). Adaptation without an understanding of the complex interactions that drive system dynamics or the range of plausible consequences can produce undesirable and increasingly unsustainable outcomes (Walker et al. 2006). Therefore, methods are needed to understand the resilience of the system's current state, search for plausible alternative future states, and evaluate these states in the context of resilience, sustainability, and societal goals. To that end, we developed a stylized agent-based model (ABM) of a tightly coupled SES to explore how the resilience of a highly engineered, seemingly locked-in, agricultural watershed emerges from the interactions among individual land users (farmers) in shifting policy and climatic contexts.

The history and applications of resilience have been capably reviewed in numerous contexts (see Cutter et al. 2010, Zhou et al. 2010, Morecoft et al. 2012). Resilience in the academic literature often takes on overlapping meanings, including a way of thinking, an organization of concepts (e.g., adaptive capacity, transformability, robustness), or a property of a system (Zhou et al. 2010, Baggio et al. 2015). Models of ecological resilience often feature a system of differential equations that describe biophysical processes, and isocline plots that identify potential states (Walker et al. 1981, Rinaldi and Scheffer 2000, Carpenter et al. 2001). These methods have been applied in a wide array of contexts, including biodiversity (Peterson et al. 1998) and catastrophic shocks to ecosystems (Scheffer et al. 2001). In these cases, human influence on the system is typically abstracted as a generator of external perturbations, and resilience is dependent on natural processes and feedbacks (Janssen and Carpenter 1999).

In geographic applications, resilience is often focused on the ability of particular places to adopt sustainable development or adaptive management practices (Adger and Vincent 2005, Gunderson et al. 2006, Anderies et al. 2013), typically in the context of global climate change or climate change-related hazards (Cutter and Finch 2008, Adger et al. 2011). Past hazard exposure and response (Cutter et al. 2010, Lam et al. 2015), and shifts in the variance of system properties are possible a priori indicators of state transitions and resilience (Carpenter and Brock 2006, Scheffer et al. 2009). Additionally, the scale and spatial structure of the SES and of the network of connected systems 
can affect a system's resilience (Cumming et al. 2006, Janssen et al. 2006). However, resilience is ultimately observable only post hoc - after a system has responded to a perturbation, maintaining or regaining the functionality of its preperturbation state or shifting to some new functional regime.

Dynamic models that integrate human behavior pose further challenges, as the heterogeneity in individual human experiences, interactions, and context is key to understanding macrolevel patterns and outcomes. The nonlinear processes and cross-scale interactions among coupled-system components create aggregate complexity (Manson 2001), which precludes deterministic modeling techniques. Therefore, we view spatially explicit modeling approaches as vital in estimating resilience and in discovering potential(dis)equilibrium states. Agent-based models provide a unique method for simulating the multiple entities, interactions, and processes that link social and ecological systems across space, time, and multiple scales. Agent-based models are useful in the resilience context because they provide a method of linking individual and social processes (e.g., markets, policymaking, power relationships, preferences) to spatially explicit land use and environmental outcomes (Parker et al. 2003), thereby addressing questions of resilience in a social-ecological context. In a following section, we develop a definition of resilience that is closely linked to the stability of system states (Holling 1973) in a complex and context-dependent setting.

\section{The stability landscape}

While ecological and social resilience are recognized as being linked (Adger 2000), there is untapped potential in operationalizing the SES perspective to explicitly consider how system-scale outcomes might emerge from social-ecological interactions (Fischer et al. 2015). Methods originally applied to ecological resilience, including the stability landscape framework (Peterson et al. 1998, Carpenter et al. 2001, Scheffer et al. 2001), can be generalized to the resilience of highly engineered SESs with complex technologies and institutions. A stability landscape is a multidimensional state space that represents all possible combinations of state variables in a system (Walker et al. 2004). Within this state space lie attractors of many sizes and shapes, representing different stability characteristics (e.g., point equilibrium, domain of attraction, runaway disequilibrium) (Holling 1973, Ives and Carpenter 2007). As these attractors exert a kind of gravitational pull on the system, some regions in state space are more likely to be occupied. In the case of equilibrium attractors, these locations are termed "basins of attraction," which are often represented as bowl-like depressions in 3dimensional state space, each corresponding to the qualitatively different quasi-stable states a system can take. The size and shape of a basin indicates the resilience of the corresponding state. For example, a deeper or wider basin represents a more resilient state than a shallow or narrow basin (Lewontin 1969, Folke et al. 2004, Menck et al. 2013). This state space is dynamic, its topography fluctuating due to changes within the SES that may affect the location or height of a basin threshold (Scheffer et al. 2001). When perturbed, a system may escape the attractor, cross the basin threshold, and reach an alternative state, which results in a functional change and a different set of controlling processes.

The stability landscape integrates a series of complex, interacting concepts and components into a cohesive, understandable conceptual framework. It is easy to imagine alternative states, the shapes of corresponding basins, and adaptations that might shift the thresholds that separate states (Fletcher et al. 2014). However, resilience, and therefore stability landscape topography, is dependent not solely on system configuration but also on the perturbation(s) of interest. Regime shifts that result from the movement of a system from one basin to another are dependent on the type, magnitude, and timing of perturbations, as well as the cumulative effects of multiple disturbances and the rate of system recovery (Scheffer et al. 2001, Folke et al. 2004). This is a distinctly "specified resilience" view, which attempts to address the resilience "of what to what" questions (Carpenter et al. 2001) that investigate resilience in particular system contexts and configurations, and to particular disturbances. Therefore, we differentiate between traditional stability landscapes that contain all possible outcomes, and a state space that considers only those states that are attainable given the interaction between a particular preperturbation state and a particular set of perturbations. This state space may not be continuous, as windows of opportunity (or disaster) may open or close, and some alternative states may not be directly reachable from the current state of the system. This approach to building stability landscapes is unlikely to find all theoretical system states. It does connect, however, the current state of a system to a particular set of disturbances and system dynamics such that major system-changing events that might push the system toward thresholds between states can be identified and analyzed.

\section{System of interest}

We used the Clear Creek Watershed (CCW), a highly instrumented and well-monitored watershed in east-central Iowa (Muste et al. 2013, Ding et al. 2015, Papanicolaou et al. 2015, Schilling et al. 2015), to represent an agricultural production system that is typical of the Midwestern United States, explore human-environment interactions, and test scenarios under the resilience framework. The current state of this SES is a landscape dominated by intensive agriculture that is focused on corn and soybean production, the functions and outputs of which are vital to the economic health and cultural identity of the region. However, the system's current configuration (or state) is likely unsustainable in the long run (Foley et al. 2011) and is subject to economic and environmental perturbations that are likely to increase in magnitude and frequency (Noble et al. 2014). Despite these perturbations, the system has remained highly productive, resilient to external disturbances, and resistant to transformation. This relative stability is a result of institutional mechanisms and technology (e.g., federal crop insurance, genetically modified crops) that reinforce the resilience and robustness of a system that promotes large scale, high yield agriculture. In this setting, farmer decisions are the primary interface through which social processes (e.g., commodity markets, government policy, social services) affect biophysical processes and landscape outcomes.

Although the CCW SES is a complex network of causal interactions and feedback loops (generalized in Fig. 1), ecological function is dominated by farming practices, technologies, and investments, and changes in these drivers can lead to alternative system states (Antle et al. 2006). The resilience of the coupled social-ecological system is the result of interactions among individual farmer practices, broad-scale policy and regulations, biophysical processes, and spatially explicit perturbations. The 
emergence of potential land use configurations and system states is the result of farmer preferences and decisions, and their ability to adapt to changing conditions within a given environmental and policy context.

Fig. 1. Simplified schematic of the social-ecological system in the Clear Creek Watershed. Farmer land use decisions provide a key coupling among biophysical and social structures and processes operating at a range of spatial and temporal scales. Arrows indicate direction of interactions and potential conduits for perturbations.

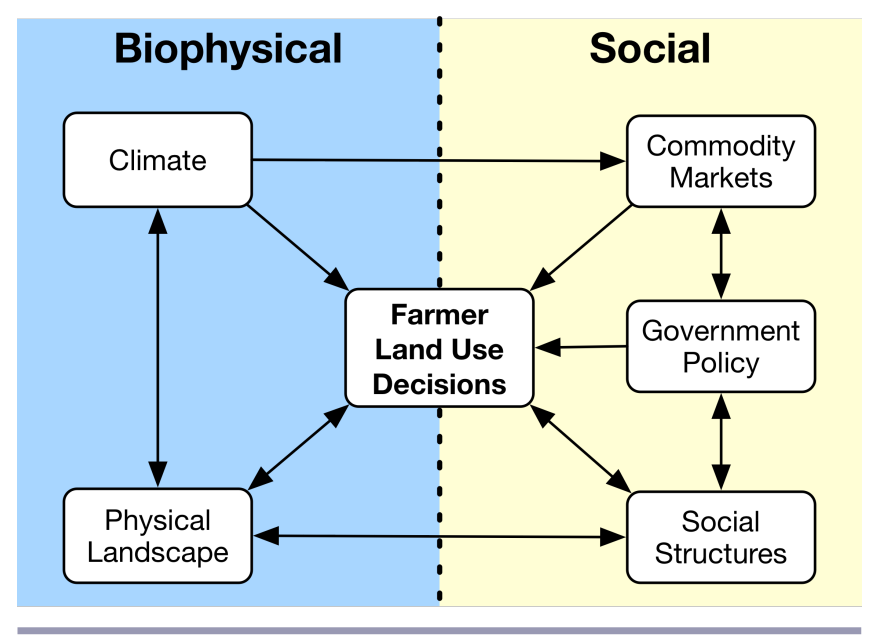

\section{Resilience in the context of the Clear Creek Watershed}

The study of resilience presents a number of conceptual and methodological challenges, the principal of which is an operational definition of resilience. As discussed, resilience is an expansive concept, growing and maturing as the work of Holling and others has developed into a complex ecosystem of related ideas, vocabularies, methods, and applications. In the context of agricultural sustainability, resilience is historically viewed as the maintenance of production despite disturbance (Conway 1985). Therefore, for the purposes of this study, we use a definition of resilience that is more closely related to engineering resilience (Gunderson 2000) or stability (Holling 1973), and define a system as resilient if it does not migrate to a new basin of attraction after being affected by a perturbation. While this definition is narrower than many in the literature (Zhou et al. 2010, Baggio et al. 2015), we argue that a more focused approach is appropriate in this context because it straightforwardly connects real-world systems to the important, but abstract, insights drawn from the stability landscape concept (i.e., distance to thresholds, relation between the magnitude of a perturbation and the likelihood of migrating to alternative basins).

The following section describes the methods used to construct and parameterize both the coupled model and scenarios of adaptation and disturbance. We then present and discuss the results of a simulation, which include resilience estimates and a series of stability landscapes for selected scenarios. By operationalizing the stability landscape framework, we are able to estimate the sensitivity of a system to perturbations, discover potential alternative system states, and characterize changes in system resilience brought on by adaptation. This method provides an initial step toward finding sustainable and resilient states for this and other social-ecological systems.

\section{METHODS}

The coupled model

Our stylized model of the agricultural SES builds upon spatially explicit and scale-dependent conceptual frameworks that view the causal linkages spanning space, scale, and social and biophysical processes as vital to understanding how coping, response, and adaptation at various scales shapes system outcomes (Turner et al. 2003, Cutter et al. 2008). Our model follows these frameworks to explore the specified resilience of the system, which integrates system and perturbation context (e.g., the nature, location, timing of a disturbance), system connectivity, and the spatial variation of relevant components and processes inside and outside the system and across multiple scales (Adger et al. 2005, Kinzig et al. 2006, Anderies et al. 2013). As environmental resilience studies have shown, state changes according to rules that govern the physical environment can generally be explained with a series of known equations (Carpenter and Brock 2006, Derissen et al. 2011). However, the inclusion of social actors and their requisite agency, power relations, and irrationality requires a methodology capable of modeling human behavior over space and scales, a task well-suited to agent-based modeling. The implementation of an ABM allows for the testing of theory, the exploration of causal explanations and uncertainty, and the discovery of unexpected outcomes in situations where shifts in climate or policy cannot be directly tested (Parker et al. 2003).

The custom ABM is written in the Java programming language. Model source code and documentation following the updated ODD protocol (Grimm et al. 2010) are hosted on openabm.org (https://www.openabm.org/model/4722/). Though the model includes many of the physical processes and components that are relevant to questions of sustainability, we focus only on those components that are most closely related to system resilience in the context of the scenarios presented. These components are (1) farmer agents and the rules governing their behavior, (2) the partitions of the physical landscape that are affected by agent decisions (i.e., farm fields), and (3) the external components that might facilitate adaptations (e.g., markets, insurance policy) or generate perturbations (e.g., drought) that affect agents and the landscape.

The primary agent class models individual farmers, each assigned a geographic location, a set of land parcels they manage at the field scale, decision criteria, and a set of actions they perform in response to stimuli. The farm field, an instantiation of a generalized land parcel class, is the spatial unit of analysis for this model. One or more fields comprise a farm, and each farm is managed by a farmer agent. Data on farmer location, tenure, and farm characteristics (e.g., crop history, field size) were used to generate a statistically representative arrangement of farms and farmer agents on the landscape to maintain subject anonymity (Ding et al. 2015). At each annual time step, farmer agents make land use decisions according to prescribed decision rules. For each potential land use, farmer agents integrate information from commodity market prices, implementation costs, past crop performance, and field characteristics to calculate the expected 
economic return from five land use options (i.e., grow corn, soybeans, or switchgrass, leave fallow, or enroll in a conservation program) for each of their fields. Corn and soybean prices are based on information from April 2015 (AGWEB 2015), while switchgrass prices are instantiated at zero but are modified according to scenarios described later. Implementation costs are estimated from Iowa State University extension data (ISU 2015a), and crop suitability ratings are used to provide yield estimates (USDA 2013). Farmer agents in this model use a simple profit maximization algorithm to choose the land use option that provides the maximum economic return for each field they manage, and remove a field from production if it has been unprofitable for three consecutive years.

After farmer agents implement their land use decisions, plots accrue both costs and natural capital (e.g., crop biomass), which results in profits (or losses) accruing to the managing farmer agent. As a model run proceeds, farmers integrate new information on actual versus expected yields and economic returns into their decision algorithm for the following year. We introduce minor stochastic variability into actualized crop yield (Bakhsh et al. 2000), implementation costs, and final commodity prices to approximate system variability, uncertainty, and minor market fluctuations. The RUSLE soil loss (Renard et al. 1991) and simplified Budyko runoff (Q) (Budyko 1958) models interface with the land parcel class, which provides field-scale estimates of biophysical effects at specific locations within the watershed. Collectively, farmers and farm fields provide a spatially explicit representation of the landscape in the $\mathrm{CCW}$, and thus, provide a model of land use, soil quality, and crop suitability.

External driving forces include prices set by commodity markets, the presence of governmental programs, and climate, each of which operates at significantly larger scales than the CCW. These external drivers are not directly modeled but form the basis for scenarios. At the scale of the $\mathrm{CCW}$, policy-makers are modeled as a single agent that makes decisions regarding prices for conservation programs and the subsidies for different land uses (e.g., start-up subsidies for switchgrass production). Initial rental rates for enrolling land in the conservation reserve program (CRP) are estimated from mean 2015 values (ISU 2015b). Drought perturbations affect the landscape, which differentially reduce biomass by land use and change coefficients in the erosional and runoff models. Each perturbation $(p)$ references the subsystem affected, the spatial extent, duration (number of time steps), and severity (degree to which the subsystem is affected). A set of perturbations $(P)$ represents a particular disturbance regime.

$$
\begin{aligned}
& \text { perturbation }=p \\
& =(\text { subsystem, spatial extent, timing, duration, severity }) \\
& \quad \text { Set of perturbations }=P=\left\{p_{1}, p_{2}, p_{3}, p_{4}, \ldots p_{n}\right\}
\end{aligned}
$$

\section{Scenarios}

We use repeated simulations to explore a range of likely system responses within the constraints of a particular scenario. Scenarios are designed to explicate the relations between system resilience and system drivers. The first set of scenarios modifies the rate of crop insurance reimbursement, the primary coping method of farmers in the system. The commodity price at which insurance is paid is subject to a number of economic and policy processes that are outside the scope of this study. Instead, we abstract the insurance system to pay farmers for losses at three levels - a baseline market price, and $75 \%$ and $50 \%$ of that baseline. Second, we model two different perturbation scenarios that represent drought. We focus on drought perturbations due to recent events (Schnoor 2012) and the likelihood such events will increase in frequency and magnitude, which potentially would result in additional crop loss and economic distress (Noble et al. 2014). The first perturbation scenario represents a $20 \%$ reduction in corn and soybean yield, which is used as a baseline and contains droughts of moderate magnitude and short duration (Al-Kaisi et al. 2013). The second perturbation scenario represents potential effects due to global climate change, and includes droughts of a greater magnitude and ranging in duration from a single year to three sequential years. Lastly, we introduce a hypothetical market for switchgrass, a cellulosic biofuel. Switchgrass is less susceptible to periods of extremely low and high moisture than are grain crops (Barney et al. 2009). Furthermore, an increase in perennial biofuels would produce more environmentally sustainable outcomes locally, and if proven economically viable, would potentially be adopted by farmers (Nelson et al. 2006, Nassauer et al. 2010). However, a market for switchgrass as a biofuel is only beginning to develop, and as such, model prices are exploratory estimates. The combinations of the three potential modifications to the system result in a set of 12 distinct scenarios. Though these scenarios and the processes they affect are simplifications of actual system dynamics, similar generalized or "stylized" models have been successfully used to explore processes of complex systems and investigate theory (Janssen 2010).

Each scenario, $S$, was parameterized with a coping capacity (insurance level), $C$, the presence of a switchgrass policy adaptation, $A$, and a perturbation regime (drought profile), $P$.

$$
\text { Scenario }=S=(C, A, P)
$$

\section{Simulation}

Each simulation is executed for a given scenario $S$, initial parameters (e.g., file locations, land use distributions), and a number of repetitions. Farmer agents select and implement a land use, parcels accumulate biomass (e.g., crops grow), and the parcels are subjected to perturbation. Farmer agents then harvest the remaining crops in the field, sell them at market prices, and balance their accounting ledgers. Profits (or losses) are distributed to the corresponding farmer agents, and coping capacity (i.e., crop insurance) is consumed if losses have occurred over the threshold set by the scenario. Farmer agents then make an individual decision whether to remain in business based on their historical performance, coping capacity, and expectations of future profitability according to experience. If net profitability for a farmer agent is negative for three consecutive years, they are removed from the simulation. The next model iteration, representing a new growing season, begins. The activity diagram in Fig. 2 plots how model components interact during simulation time.

Each scenario is repeated 1000 times, resulting in 12,000 total models runs. The repeated model runs allows for the exploration of effects of initial conditions and stochastic processes (e.g., realized yield) on model outcomes and the location of attractors on the stability landscape. For each run, the model was allowed to "spin up" and reach a basin of attraction. In our simulations, the model quickly (generally within 20 time steps) attains a dynamic equilibrium, as observed by stable landscape 
configuration and aggregate system-scale income. Once dynamic equilibrium is attained, we perturb the system by introducing an artificial drought. The timing of perturbation is stochastically varied, which ensures that over repeat runs of the scenario, disturbances occur while the system occupies different locations relative to basin thresholds, and potentially produces different outcomes. The simulation records model outputs related to dimensions of economic productivity, landscape configuration, and environmental outcomes. The software also derives summary statistics for each scenario, including the proportion of model runs where the system crossed a predetermined threshold and failed to return to the preperturbation dynamic equilibrium.

Fig. 2. Model activity diagram describing interactions among model components during the simulation of a scenario. Black bars indicate points of divergence or reconvergence of parallel processes.

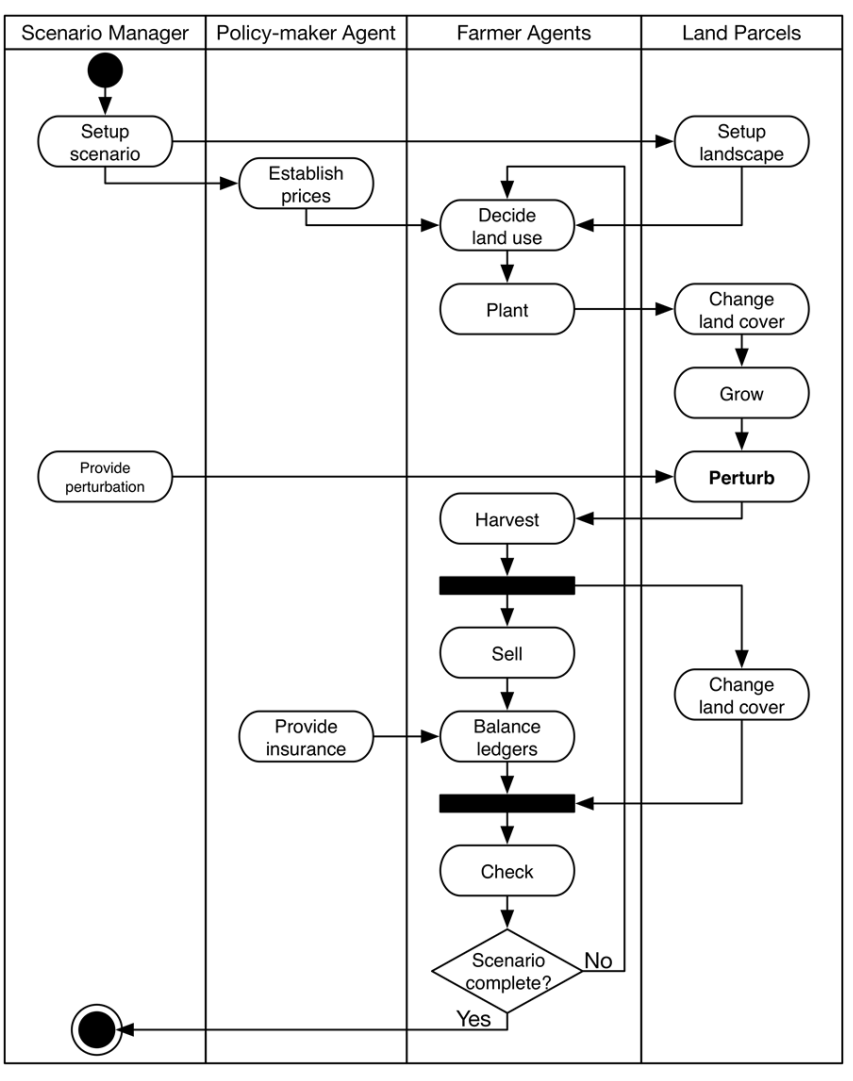

\section{Simulated outcomes in state space}

If state space attractors are present, then systems will tend to gravitate toward them over time. Therefore, stable (or quasistable) attractors can be identified by observing the movement of a system toward a particular area in state space (Ives and Carpenter 2007). Prior to the application of the scenarios or simulated droughts, we explore model sensitivity via a grid search of initial conditions (i.e., commodity prices, subsidy levels), and plot simulation outcomes and attractors in state space. Tracing a system's path from initial conditions to an attractor is straightforward, requiring a plot of the system's location in state space over time against key dimensions (sensu Janssen and
Carpenter 1999), and many traces can in aggregate begin to provide insight into the effects of initial conditions and model parameterization on both the locations of attractors in state space and landscape configuration (Malanson et al. 2006). Fig. 3 plots one such trace, as well as the aggregate end points of simulations, approximating the locations of alternative states and preperturbation basins of attraction for the given model parameters. All analyses and figures were created in the R 3.2.3 software environment ( $\mathrm{R}$ Core Team 2015). The independent density curves of simulation end points along each axis in Figs. 4, 7-8 are created using the "nrd0" method in the R "stats" package. Within the two distinct zones in Fig. 3, smaller clusters of outcomes are the result of the discretization of the physical landscape in farm fields and of the grid search through input space.

Any visualization of the state space is a projection from a simulated hyperspace. Though both the SES and our model exist in a highly dimensional space, we constrain our analysis of the system to two dimensions for the purposes of visualization. These dimensions are related to system resilience at different spatial scales and illustrate trade-offs between ecological diversity and economic optimization. The first dimension is mean net profit, a proxy for the economic viability of the current configuration of the agricultural system as a whole. Individual farmers without the economic means to absorb perturbations, maintain productivity, and adapt will likely not be resilient. Collectively, the economic resilience of farmers reflects the effectiveness of insurance in providing short-term economic stability. The second dimension is the diversity of the landscape as quantified by the Modified Simpson Diversity Index (MSIDI) (Pielou 1975). The MSIDI measures the heterogeneity of the landscape, and is defined as the negative natural logarithm of the probability that two randomly selected patches belong to the same land cover type. A higher MSIDI value indicates a more equitable distribution of land cover types. A diverse agricultural landscape possessing greater functional and response diversity is likely to be more resilient to a disturbance than a landscape containing a single crop (Elmqvist et al. 2003). The MSIDI is calculated as follows:

$$
M S I D I=-\ln \sum_{i=1}^{m} P_{i}^{2}
$$

where $m$ is the number of potential land uses ( 5 , in this model) and $P_{i}$ is the proportion of the landscape occupied by land class $i$. The distribution of simulation outcomes in state space approximates attractors in the chosen dimensions and the general stability of system processes to inputs. In this space, each point in state space corresponds to a realization of the actual landscape at the end of a given simulation. For example, a simulation resulting in the landscape in Fig. $4 \mathrm{~B}$ is found within the attractor in the left portion of the state space, while the landscape configuration in Fig. 4C lies in the right-hand attractor, and results in greater economic productivity. This process is useful for locating attractors, and exploring the effects of initial conditions on eventual system outcomes and the equifinality or multifinality of simulation end points (e.g., do different initial conditions lead to the same end result). Similarly, each simulation, as defined in Eq. 2, results in a corresponding state space, potentially containing a set of attractors, and determined by the parameterization of the scenario (e.g., policy), as well as the simulated perturbation regime. 
Fig. 3. A single trace of a model run through state space (solid line) overlaid with outcomes of other model runs (open circles) that result from the grid search of input parameters. Two distinct attractors are found in this state space, with smaller attractors nested within each. (MSIDI: Modified Simpson Diversity Index)
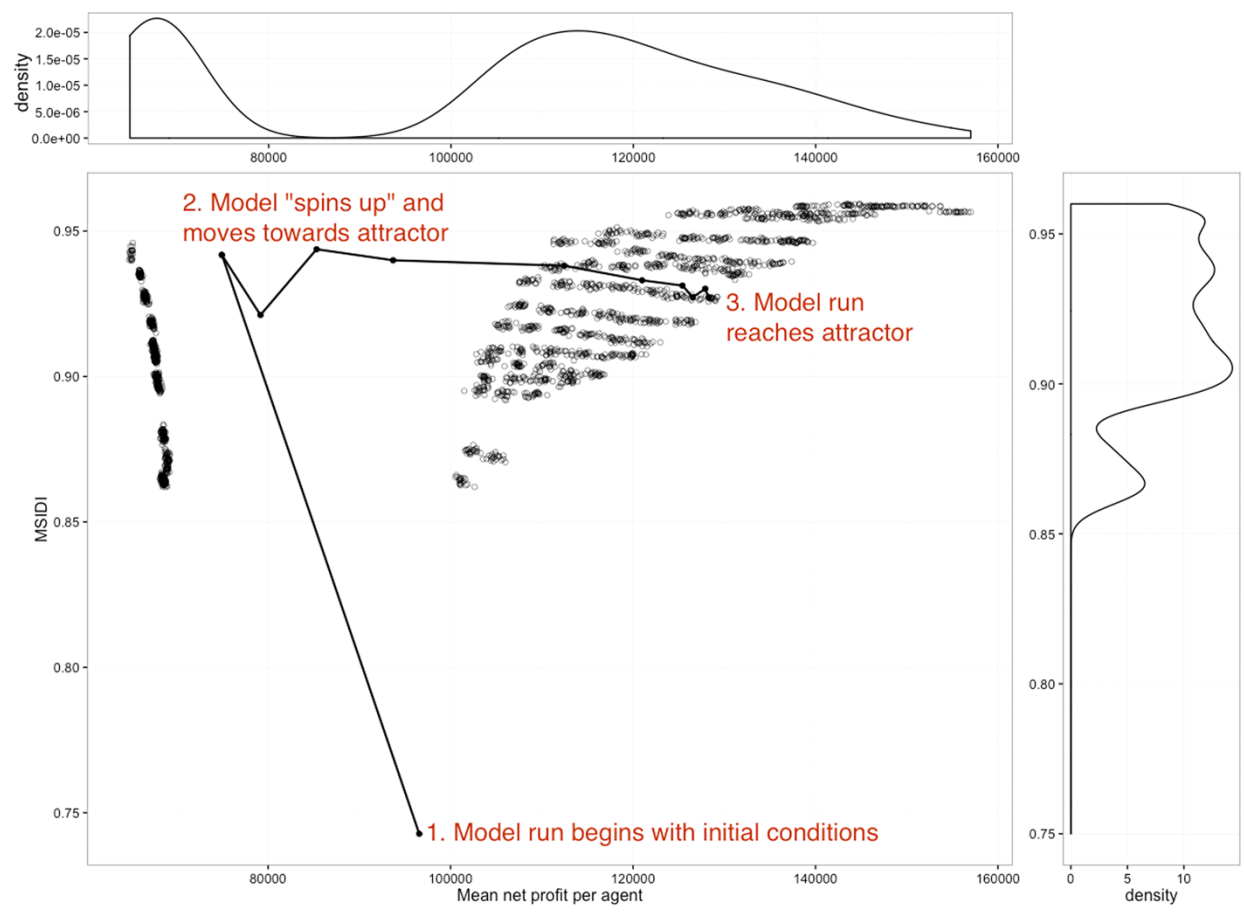

Fig. 4. (A) The same end points of the simulations produced via the grid search of input parameters and presented in Figure 3 correspond to alternative configurations of land use in the Clear Creek Watershed. (B) One realization of the landscape with lower mean profitability and a greater proportion of switchgrass. (C) An alternative model outcome residing in the other attractor, dominated by corn and resulting in higher mean profits.

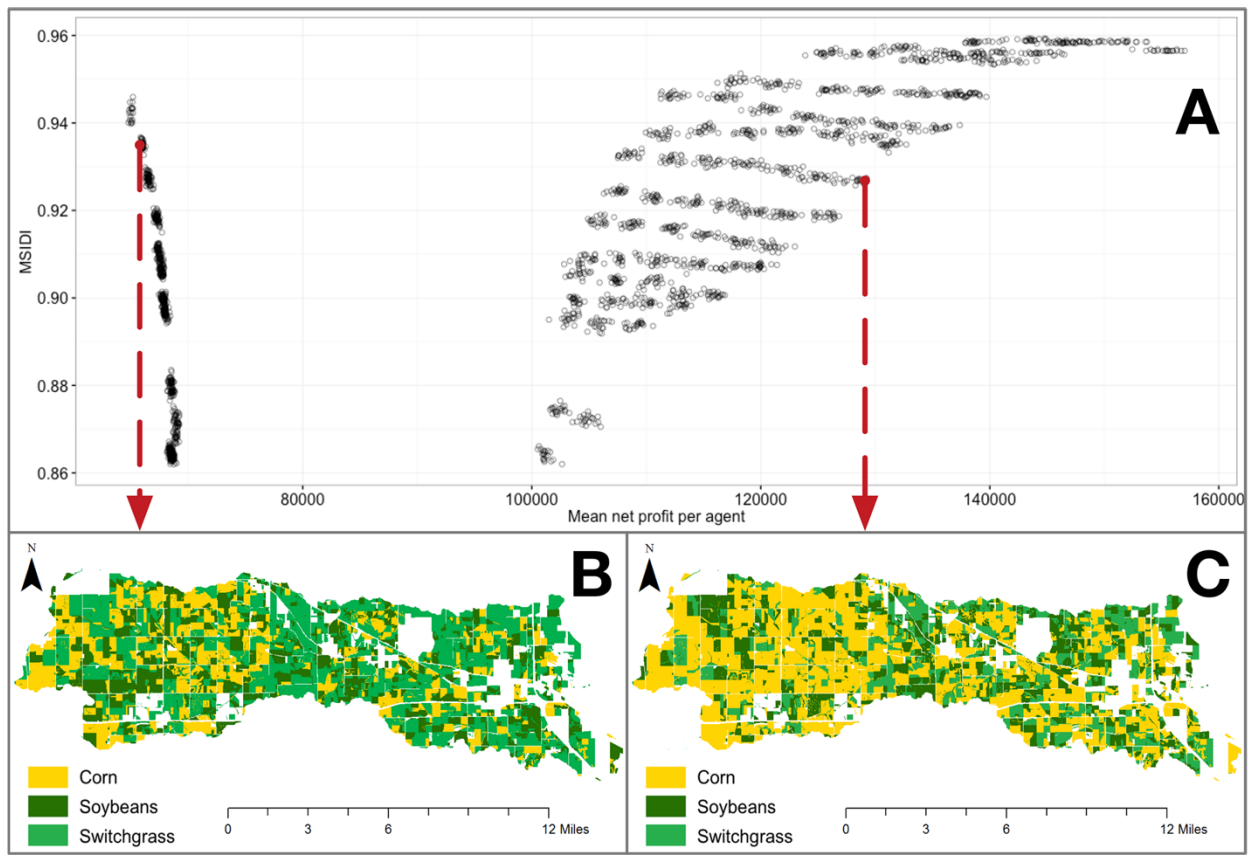


Fig. 5. Distributions of the proportions of farmers who are resilient to perturbations (remaining in business at the end of the simulation) by scenario. Farmers in the scenarios affected by the baseline perturbation regime (S1, S5, and S8) are generally more resilient than those (S2, S6, and S10) affected by the alternative (and greater) perturbation regime. The relative lower sensitivity of switchgrass to simulated droughts results in a greater number of resilient farmers in those scenarios (S3, S4, S7, S8, S11, and S12). Each scenario was simulated 1000 times.

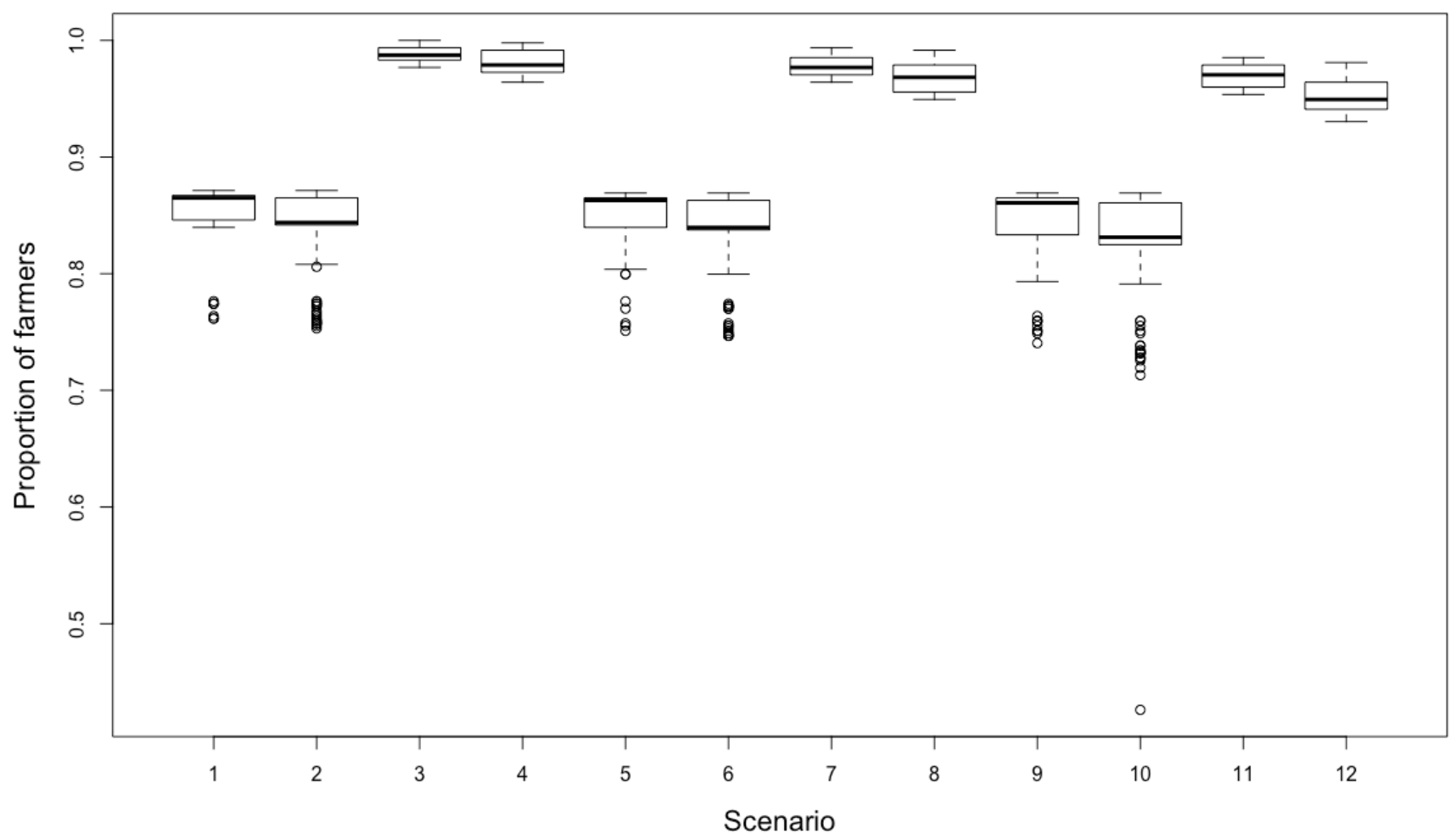

\section{Stability landscapes and perturbations}

To model system resilience to perturbations, we introduce the simulated droughts as parameterized by the scenarios in Table 1. For each run of the simulation, the model is (1) allowed to reach a dynamic equilibrium, (2) perturbed upon reaching equilibrium, and (3) tracked from the moment of perturbation. If the system returns to its dynamic equilibrium, then it is considered resilient. If resilience is overcome, however, the system moves to a new state, and we expect additional clusters in state space that exhibit high outcome densities (May 1977). For each repetition of the simulation, we plot system trajectory through state space, and over many Monte Carlo simulations (1000 for each scenario), we map the same number of postperturbation outcomes and construct a state space for each scenario.

These state spaces differ from traditional stability landscapes in two ways. First, they do not show all potential outcomes for the modeled system. Instead, they display the range of outcomes given a particular preperturbation state and the set of perturbations. While this is a decidedly "resilience of what to what" approach (Carpenter et al. 2001), it is dependent on the assumptions and simplifications inherent in the modeling process.
Table 1. Scenarios

\begin{tabular}{cccc}
\hline \hline Scenario & $\begin{array}{c}\text { Coping capacity } \\
(\mathrm{C})\end{array}$ & $\begin{array}{c}\text { Switchgrass } \\
\text { market }(\mathrm{A})\end{array}$ & $\begin{array}{c}\text { Perturbation } \\
\text { regime }(\mathrm{P})\end{array}$ \\
\hline $\mathrm{S}_{1}$ & market baseline & status quo & baseline \\
$\mathrm{S}_{2}$ & market baseline & status quo & alternative \\
$\mathrm{S}_{3}$ & market baseline & alternative & baseline \\
$\mathrm{S}_{4}$ & market baseline & alternative & alternative \\
$\mathrm{S}_{5}$ & $0.75 *$ baseline & status quo & baseline \\
$\mathrm{S}_{6}$ & $0.75 *$ baseline & status quo & alternative \\
$\mathrm{S}_{7}$ & $0.75 *$ baseline & alternative & baseline \\
$\mathrm{S}_{8}$ & $0.75 *$ baseline & alternative & alternative \\
$\mathrm{S}_{9}$ & $0.50 *$ baseline & status quo & baseline \\
$\mathrm{S}_{10}$ & $0.50 *$ baseline & status quo & alternative \\
$\mathrm{S}_{11}$ & $0.50 *$ baseline & alternative & baseline \\
$\mathrm{S}_{12}$ & $0.50 *$ baseline & alternative & alternative \\
\hline
\end{tabular}

Second, system trajectory through state space and between basins is path dependent, and the interbasin state space is therefore likely discontinuous. Despite its limitations, this method allows us to characterize the resilience of the system of interest in its current 
Fig. 6. Stability landscapes for scenarios that include status quo land use policy (no switchgrass market). Scenarios in the left column are affected by the baseline perturbation regime; scenarios in the right column are affected by the alternative. Insurance reimbursement rates range from top to bottom by row at $100 \%, 75 \%$, and $50 \%$, respectively. Landscape configuration (basin topography) is affected by a change in perturbation severity, while changes in coping capacity result in similarly shaped density curves that shift position along the axes. (MSIDI: Modified Simpson Diversity Index)
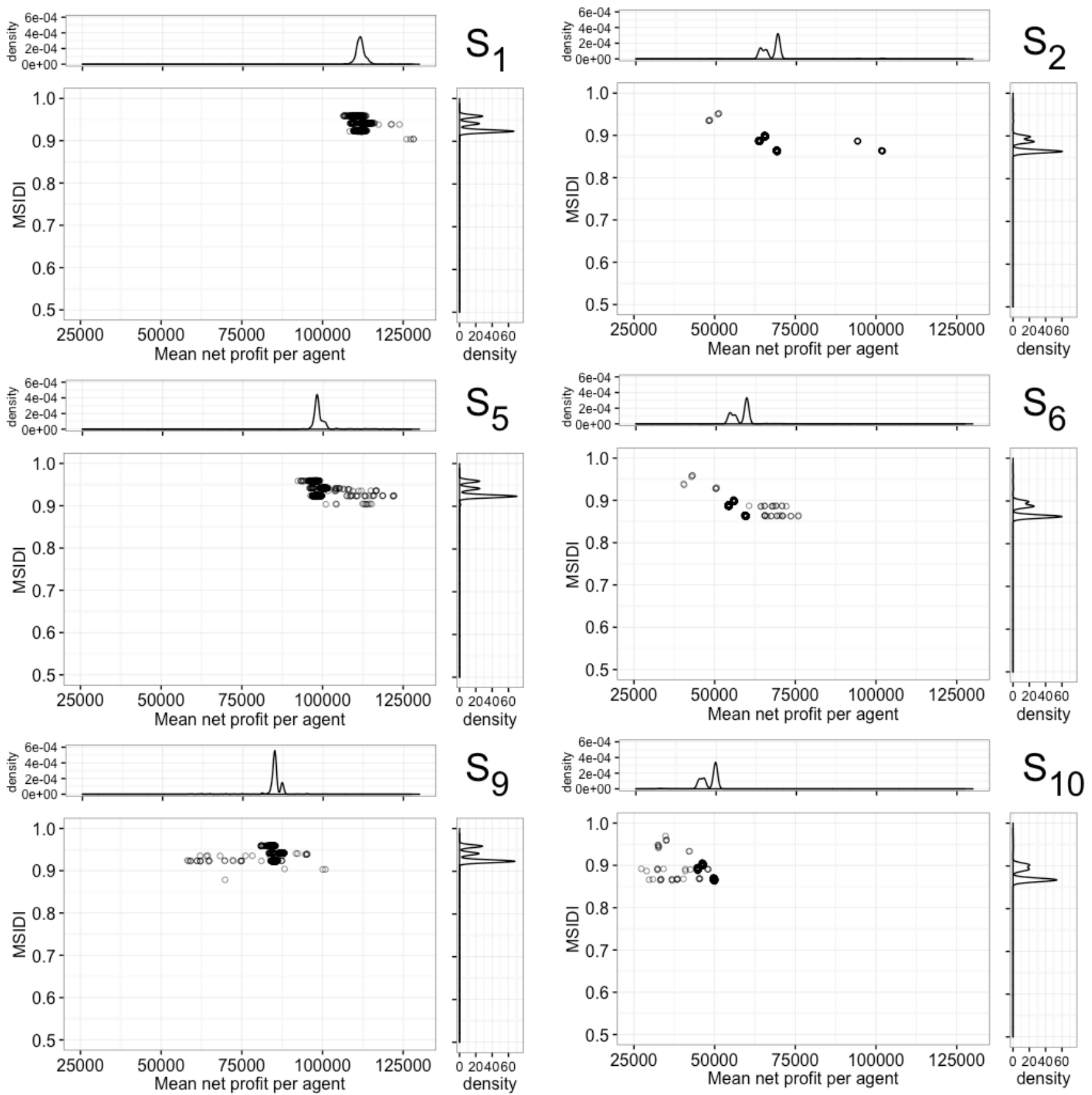

state and to a particular set of perturbations. State space morphology can be a guide for understanding model response and system resilience. For example, simulation outcomes that occur near an original attractor site would suggest a resilient system state in the given context. Similarly, a more heterogeneous landscape with many potential outcome states (i.e., many basins) indicates a larger variance in model response to perturbation, and potentially a less resilient system.

\section{RESULTS}

Model outputs can be analyzed at the field, farm, or watershed scales. We first view the outcomes of our simulation by 
Fig. 7. Stability landscapes for scenarios that introduce an artificial market for switchgrass. The baseline perturbation regime is on the left; the alternative is on the right. Coping capacity diminishes from the top row to the bottom. Landscape configuration (as measured by MSIDI: Modified Simpson Diversity Index) remains stable, though less so than as seen in Fig. 6.
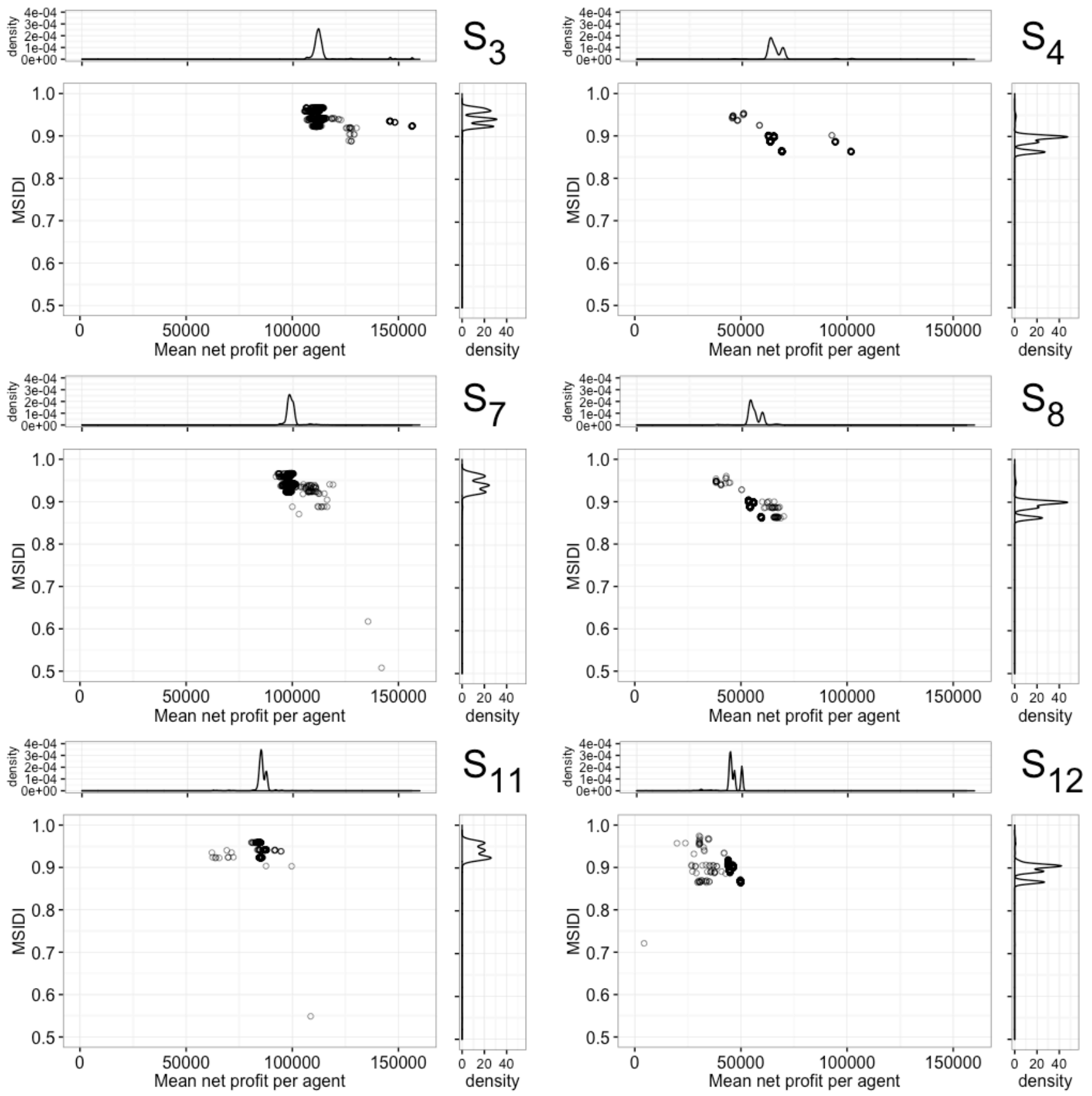

aggregating the effects of perturbations and insurance reimbursement levels on individual farmer agent outcomes. The boxplots in Fig. 5 display the proportion of farmer agents that were resilient (defined as remaining in business at the end of the simulation) in the repeated model runs for each scenario. A reduction in the insurance reimbursement level resulted in a lower proportion of agents that were able to bounce back after the simulated drought. Larger perturbations also resulted in additional farmers exhausting their coping capacity and going out of business (e.g., a greater proportion of farmer agents were resilient in scenario $S_{9}$ than in $S_{10}$ ). The presence of a market for less drought-sensitive switchgrass resulted in more resilient farmers as well $\left(\mathrm{S}_{3}, \mathrm{~S}_{4}, \mathrm{~S}_{7}, \mathrm{~S}_{8}, \mathrm{~S}_{11}\right.$, and $\left.\mathrm{S}_{12}\right)$.

Shifting to watershed or system-scale outcomes, Fig. 6 shows the changes in stability landscapes for the six scenarios that used 
Fig. 8. Two different stability landscapes for Scenario 12, created with mean profitability (left) and the standard deviation of profitability (right). While variable selection might affect state space configuration, in this case the spaces have similar structures due to their high correlation $(r=0.95)$. This suggests that in model runs where mean profitability is higher after a perturbation, farmer outcomes are highly skewed and less equitable because the larger operators were resilient. (MSIDI: Modified Simpson Diversity Index)
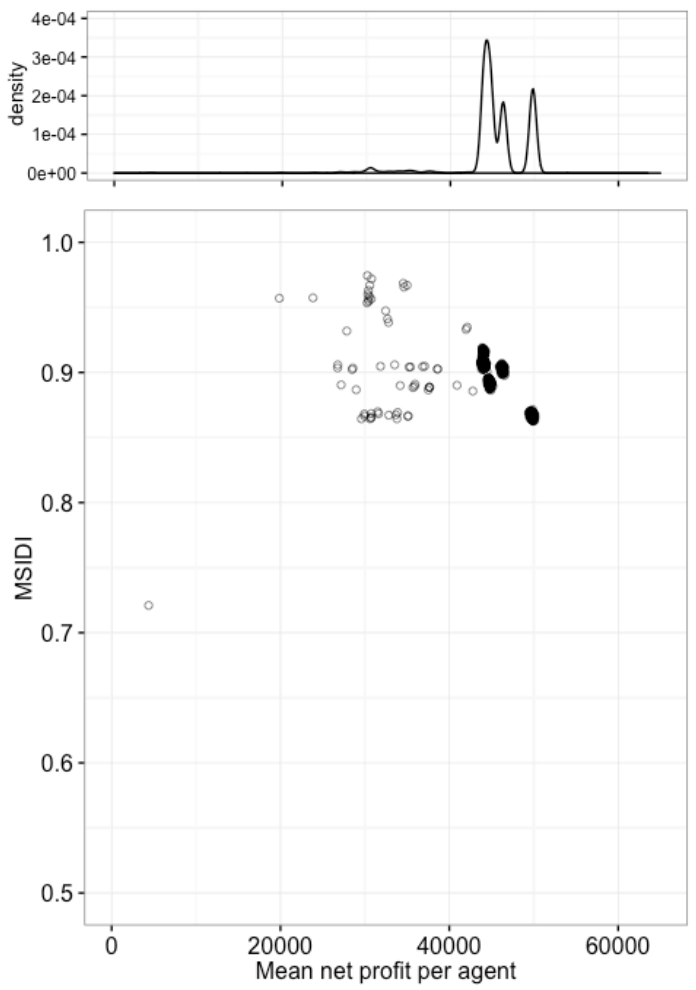

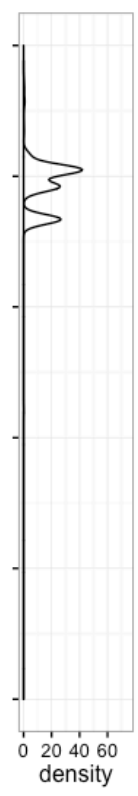

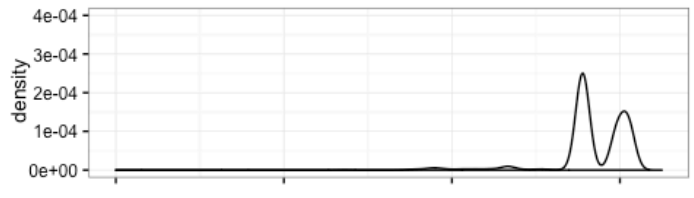
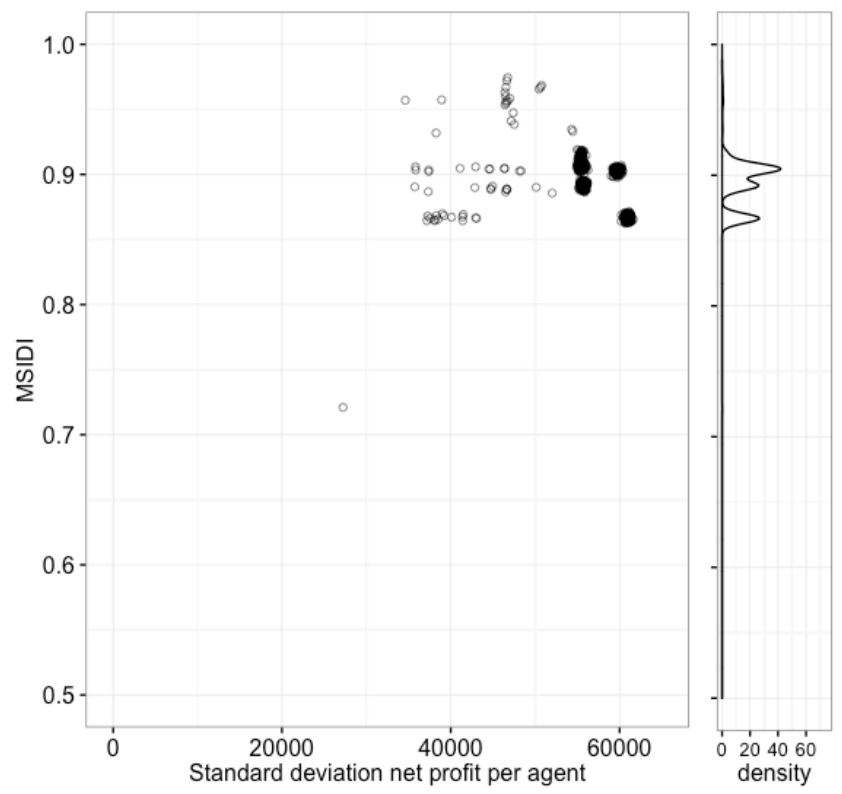

status quo land use policy (i.e., no switchgrass market). Scenarios in the first column $\left(\mathrm{S}_{1}, \mathrm{~S}_{5}\right.$, and $\left.\mathrm{S}_{9}\right)$ used baseline perturbations, while the other scenarios $\left(\mathrm{S}_{2}, \mathrm{~S}_{6}\right.$, and $\left.\mathrm{S}_{10}\right)$ included the alternative, more severe droughts. Land use diversity as measured by MSIDI was relatively consistent among scenarios with the same perturbation regimes. However, the reduction in coping capacity resulted in a decrease in mean profitability per agent (e.g., $\mathrm{S}_{1}$ versus $S_{9}$ ). Similarly, the increase in perturbation intensity resulted in a decrease in mean profits and an increase in profit variability.

Fig. 7 shows the results of simulations that included the artificial switchgrass market. As before, more intense perturbations $\left(\mathrm{S}_{4}, \mathrm{~S}_{8}\right.$, and $S_{12}$ ) resulted in lower and more variable profits. Though the profitability of the switchgrass scenarios was similar to the status quo profits in Fig. 6, the distributions of simulation outcomes were tighter, indicating an increased stability due to farmers choosing to plant switchgrass. However, the introduction of an alternative land use unexpectedly reduced landscape diversity, a result of many farmer agents choosing to plant the perennial grass, an unlikely outcome resulting from the simplified market dynamics in the model. These subtleties in the simulation results require careful interpretation, as the structure of agent decisions rules and variable selection strongly influence the shape of the stability landscape.

\section{DISCUSSION}

Methods to measure resilience essentially fall into two categories (Morecroft et al. 2012). The first is the amount of time it takes to recover from a perturbation. The second is the amount of disturbance a system can be subjected to and remain functioning in the same manner. An extension of the latter defines a probabilistic resilience, which is "...the probability that a state will persist" (Peterson 2002). Our outcome spaces operationalize this second view of resilience by characterizing the stability of the system absent perturbation inputs (Fig. 5), as well as the distributions of postperturbation states in particular perturbation and policy contexts (Figs. 6 and 7).

Functionally, system-scale resilience emerges from interactions across a panarchy of components, both internal and external to the complex adaptive system (Holling 2001). In the CCW, land use decisions are made and coping capacity is consumed at the farm or farmer scale, which collectively shapes landscape morphology and trajectory. However, the individual resilience of farmer agents also occurs within the context of top-down policy and broad-scale climate that combine to affect watershed-scale outcomes. To this end, the proportion of resilient farmer agents in different scenarios provides one window into the efficacy of individual agent behavior within a particular policy and economic context (Fig. 5), and against a predetermined threshold for individual resilience (when farmer agents quit farming). While 
this is a stylized model, we recognize any such threshold is contextually dependent on culture, time, and location, and should include stakeholders to address the question "resilience of what, to what, and who decides" (Davoudi et al. 2012). Fuzzy cognitive mapping (FCM) methods have proven useful in identifying desirable alternative states, identifying thresholds, and addressing questions of context by involving stakeholders in modeling system dynamics (Gray et al. 2015), and would be interesting future work. However, FCMs are currently aspatial and the alternative states they identify may not represent equilibrium conditions.

The results of our simulations were generally as expected, as the resilience of agents was lower in the scenarios where coping capacity (crop insurance) was reduced. The scenarios where land use changed in response to the introduction of a switchgrass market appear to indicate an increase in resilience (as seen in a more homogenous stability landscape). However, this may be due to a change in robustness brought on by the introduction of switchgrass, which is less drought-sensitive than alternative crops, and not indicative of agent resilience to the perturbation. Regardless, in the cases where the system included the switchgrass market, higher crop diversity led to greater income stability of agents in the watershed, which prevented more farmers from going out of business while maintaining a potential buffer against other types of perturbations that were unexplored in this study (e.g., price fluctuations).

Though Fig. 5 suggests a watershed-scale shift from row crops to switchgrass would improve aggregate farmer stability, an adaptation of that nature and magnitude would be unlikely at much larger scales, as consumer demand and other market forces would drive at least a portion of the landscape to traditional row crops. Similarly, our results suggest unlimited and inexpensive crop insurance would increase SES resilience in the near term. While insurance is vital to maintaining economic viability, it is also reasonable to expect the guaranteed economic return may reinforce current modes of industrial agriculture and erode longer term resilience and create poor environmental outcomes ( $\mathrm{Wu}$ 1999, McLeman and Smit 2006). Agriculture in the study area has been engineered to be resilient to perturbation in pursuit of maintaining a particular goal-yield. However, this optimization has resulted in unsustainable outcomes and spatial externalities, such as hypoxic conditions in the Gulf of Mexico due to nutrient runoff (Rabalais et al. 2002). This consideration of spatial and temporal lags and scales recalls the "resilience of what to what" question (Carpenter et al. 2001) and requires the consideration of the full panarchy of systems to find truly sustainable solutions (Walker et al. 2004).

While ABMs are well-suited for representing hierarchical system dynamics, they have some limitations in geographic applications. As with any model, ABMs are dependent on the amount of information available on the system being modeled. Further, the model must be constructed at the correct level of abstraction with respect to component and process complexity (Couclelis 2002). Our stylized model ameliorates some of the concerns by simplifying the decision-making process and biophysical models, though our assumptions of profit maximization and economically rational behavior precludes some alternative land use decisions and adaptations. While the intent of our model is illustrative and exploratory, a more complex decision model, while introducing additional parameters and concomitant data requirements, would likely produce a more realistic range of outcomes and alternative states. The use of survey data, for example, could produce classes of farmers who possess different resources, preferences, and decisions hierarchies, and is the focus of future research. Agent-based models can also be highly sensitive to initial conditions and the rules that govern agentagent and agent-environment interactions. Here, our approach to constructing stability landscapes can be a useful tool in the preliminary exploration of the effect of these limitations on system dynamics.

The state spaces we present are dependent on variable selection and the choice of summary statistics (e.g., variance, mean). Our selections of mean agent profitability and landscape diversity (measured by MSIDI) are but two of many potential output variables from the model, and the stability landscapes would have a different form if other choices were made. The diversity of a landscape is clearly related to its resilience (Elmqvist et al. 2003). However, by calculating the mean income of farmer agents in the $\mathrm{CCW}$ as the second dimension, we potentially lose information related to heterogeneity of agent response. However, as shown in Fig. 8, separate state spaces constructed with the mean and standard deviation of profits in scenario 12 have similar structures. This is due to a high correlation between these dimensions $(r=0.95)$, meaning that as the average profitability increases, farmers see increasingly disparate outcomes because the larger operators were more resilient to the simulated drought. While insurance polices are purchased by individual farmers, policy goals are aimed at system-scale functionality, and our stability landscapes visualize the current state of the CCW, which is dominated by corn and soybeans in industrial agricultural operations. Therefore, we selected as our key variables those that change during a simulation-land use choice in response to prices or policy, and profitability due to drought perturbations. We acknowledge, however, the unrepresented dimensions in this state space (e.g., environmental conditions). Further, what appears to be an attractor in two-dimensions may actually be many distinct attactors in a higher dimensional space. Despite their limitations, we view these stability landscapes as useful exploratory and diagnostic tools during the modeling processes, which allow modelers to visualize system sensitivity to initial conditions, path dependence, and perturbations using methods similar to quantifying landscape metrics (Brown et al. 2005), applied to an artificial state space.

\section{CONCLUSION}

Physical landscapes are the result of natural and social processes operating within nested systems at different spatial and temporal scales. If we aim to adapt our systems to be more sustainable, then we need to understand the ways in which complex socialecological systems transition from one state to the next and how those state changes ripple through connected systems and across space and time. There may be multiple paths toward the goal of sustainability, and each state transition should consider the set of paths leading from the current state to the objective. However, we must also consider the possibility of paths leading to positive effects at one scale but negative outcomes at other scales or in other systems. Furthermore, not all improvements in resilience are necessarily desirable, as a change in the resilience of a single 
system may result in amplifying or dampening the resilience of other systems in unpredictable ways (Gunderson and Holling 2002). Similarly, a system state that is unsustainable along numerous dimensions may also be valued for a particular output and be highly resilient to perturbations or resistant to adaptation.

If understanding the resilience of social-ecological systems is important to future human and environmental well-being, then we require methods to estimate it under different disturbance regimes and in response to possible adaptations. These methods should incorporate spatiotemporal context, the complex dynamics of the social-ecological systems, and the increasing influence of human activity on the environment. The model and method of constructing stability landscapes we have presented has incorporated social process and individual decision-making with biophysical models to describe SES resilience under various scenarios. While "slow" variables may control ecosystem function, legacy, and diversity (Folke et al. 2002), human actions have the potential to accelerate the rate at which slow variables change and propel systems toward key thresholds (Brock 2006, Carpenter and Brock 2006, Folke 2006). By coupling an agentbased model to biophysical models, we have used stability landscapes to visualize the effects of comparatively "fast" moving processes on system state. These landscapes are one tool in a suite of methods that are necessary to understand the effects of policy on SES trajectory relative to alternative stable states without the need to predefine those states. Lastly, this method can be used to investigate trade-offs among potential proposed adaptations, a function especially important because SESs cannot be built to be resilient to all perturbations, or cannot be truly sustainable forever.

Responses to this article can be read online at: http://www.ecologyandsociety.org/issues/responses. $\mathrm{php} / 8677$

\section{Acknowledgments:}

We sincerely thank the editor, subject editor, and three anonymous reviewers for their constructive comments and suggestions. This work is funded in part by NSF Coupled Natural Human Systems Award \#1114978, People, Water, and Climate: Adaptation and Resilience in Agricultural Watersheds.

\section{LITERATURE CITED}

Adger, W. N. 2000. Social and ecological resilience: are they related? Progress in Human Geography 24(3):347-364. http://dx. doi.org/10.1191/030913200701540465

Adger, N., N. W. Arnell, and E. L. Tompkins. 2005. Successful adaptation to climate change across scales. Global Environmental Change 15(2):77-86. http://dx.doi.org/10.1016/j.gloenvcha.2004.12.005

Adger, W. N., K. Brown, D. R. Nelson, F. Berkes, H. Eakin, C. Folke, K. Galvin, L. Gunderson, M. Goulden, K. O'Brien, J. Ruitenbeek, and E. L. Tompkins. 2011. Resilience implications of policy responses to climate change. Wiley Interdisciplinary Reviews: Climate Change 2(5):757-766. http://dx.doi.org/10.1002/ $\underline{\text { wcc. } 133}$
Adger, W. N., and K. Vincent. 2005. Uncertainty in adaptive capacity. Comptes Rendus Geoscience 337(4):399-410.

AGWEB. 2015. Cash Grain Bids. [online] Available at: http:// www.agweb.com/markets/cash-grain-bids/

Al-Kaisi, M. M., R. W. Elmore, J. G. Guzman, H. M. Hanna, C. E. Hart, M. J. Helmers, E. W. Hodgson, A. W. Lenssen, A. P. Mallarino, A. E. Robertson, and J. E. Sawyer. 2013. Drought impact on crop production and the soil environment: 2012 experiences from Iowa. Journal of Soil and Water Conservation 68(1):19A-24A. http://dx.doi.org/10.2489/jswc.68.1.19A

Allison, H., and R. Hobbs. 2004. Resilience, adaptive capacity, and the "lock-in" trap of the Western Australian agricultural region. Ecology and Society 9(1):3. [online] URL: http://www. ecologyandsociety.org/vol9/iss 1/art3/

Anderies, J. M., C. Folke, B. Walker, and E. Ostrom. 2013. Aligning key concepts for global change policy: robustness, resilience, and sustainability. Ecology and Society 18(2):8. http:// dx.doi.org/10.5751/es-05178-180208

Antle, J. M., J. J. Stoorvogel, and R. O. Valdivia. 2006. Multiple equilibria, soil conservation investments, and the resilience of agricultural systems. Environment and Development Economics 11 (4):477-492. http://dx.doi.org/10.1017/s1355770x06003056

Baggio, J. A., K. Brown, and D. Hellebrandt. 2015. Boundary object or bridging concept? A citation network analysis of resilience. Ecology and Society 20(2):2. http://dx.doi.org/10.5751/ es-07484-200202

Bakhsh, A., D. B. Jaynes, T. S. Colvin, and R. S. Kanwar. 2000. Spatio-temporal analysis of yield variability for a corn-soybean field in Iowa. Transactions of the ASAE 43(1):31-38. http://dx. doi.org/10.13031/2013.2684

Barney, J. N., J. J. Mann, G. B. Kyser, E. Blumwald, A. Van Deynze, and J. M. DiTomaso. 2009. Tolerance of switchgrass to extreme soil moisture stress: ecological implications. Plant Science 177(6):724-732. http://dx.doi.org/10.1016/j.plantsci.2009.09.003

Bennett, E. M., G. D. Peterson, and L. J. Gordon. 2009. Understanding relationships among multiple ecosystem services. Ecology Letters 12:1394-1404. http://dx.doi.org/10.1111/ j.1461-0248.2009.01387.x

Brock, W. A. 2006. Tipping points, abrupt opinion changes, and punctuated policy change. Pages 47-77 in R. Repetto, editor. Punctuated equilibrium and the dynamics of U.S. environmental policy. Yale University Press, New Haven, Connecticut, USA.

Brown, D., S. Page, R. Riolo, M. Zellner, and W. Rand. 2005. Path dependence and the validation of agent-based spatial models of land use. International Journal of Geographical Information Science 19(2):153-174. http://dx.doi.org/10.1080/13658810410001713399

Budyko, M. I. 1958. The heat balance of the Earth's surface. U. S. Department of Commerce, Washington, D.C., USA.

Carpenter, S. R., and W. A. Brock. 2006. Rising variance: a leading indicator of ecological transition. Ecology Letters 9(3):311-318. http://dx.doi.org/10.1111/j.1461-0248.2005.00877.x

Carpenter, S. R., and W. A. Brock. 2008. Adaptive capacity and traps. Ecology and Society 13(2):40. [online] URL: http://www. ecologyandsociety.org/vol13/iss2/art40/ 
Carpenter, S. R., H. A. Mooney, J. Agard, D. Capistrano, R. S. Defries, S. Díaz, T. Dietz, A. K. Duraiappah, A. Oteng-Yeboah, H. M. Pereira, C. Perrings, W. V Reid, J. Sarukhan, R. J. Scholes, and A. Whyte. 2009. Science for managing ecosystem services: beyond the Millennium Ecosystem Assessment. Proceedings of the National Academy of Sciences 106(5):1305-1312. http://dx. doi.org/10.1073/pnas.0808772106

Carpenter, S., B. Walker, and J. M. Anderies, and N. Abel. 2001. From metaphor to measurement: resilience of what to what? Ecosystems 4(8):765-781. http://dx.doi.org/10.1007/s10021-001-0045-9

Conway, G. R. 1985. Agroecosystem analysis. Agricultural Administration 20(1):31-35. http://dx.doi.org/10.1016/0309-586x (85)90064-0

Couclelis, H. 2002. Modelling frameworks, paradigms, and approaches. Pages 36-50 in K. C. Clarke, B. E. Parks, and M. P. Crane, editors. Geographic information systems and environmental modelling. Prentice Hall, London, UK.

Cumming, G. S., D. H. M. Cumming, and C. L. Redman. 2006. Scale mismatches in social-ecological systems: causes, consequences, and solutions. Ecology and Society 11(1):14. [online] URL: http://www.ecologyandsociety.org/vol11/iss1/ art14l

Cutter, S. L., L. Barnes, M. Berry, C. Burton, E. Evans, E. Tate, and J. Webb. 2008. A place-based model for understanding community resilience to natural disasters. Global Environmental Change 18(4):598-606. http://dx.doi.org/10.1016/j.gloenvcha.2008.07.013

Cutter, S. L., C. G. Burton, and C. T. Emrich. 2010. Disaster resilience indicators for benchmarking baseline conditions. Journal of Homeland Security and Emergency Management 7 (1):51.

Cutter, S. L., and C. Finch. 2008. Temporal and spatial changes in social vulnerability to natural hazards. Proceedings of the National Academy of Sciences of the United States of America 105(7):2301-2306. http://dx.doi.org/10.1073/pnas.0710375105

Davoudi, S., K. Shaw, L. J. Haider, A. E. Quinlan, G. D. Peterson, C. Wilkinson, H. Fünfgeld, D. McEvoy, and L. Porter. 2012. Resilience: a bridging concept or a dead end? "Reframing" resilience: challenges for planning theory and practice interacting traps: resilience assessment of a pasture management system in northern Afghanistan urban resilience: What does it mean in planning practice? Resilience as a useful concept for climate change adaptation? The politics of resilience for planning: a cautionary note. Planning Theory \& Practice 13(2):299-333. http://dx.doi.org/10.1080/14649357.2012.677124

DeFries, R. S., J. A. Foley, and G. P. Asner. 2004. Land-use choices: balancing human needs and ecosystem function. Frontiers in Ecology and the Environment 2(5):249-257. http://dx. doi.org/10.1890/1540-9295(2004)002[0249:Icbhna]2.0.co:2

Derissen, S., M. F. Quaas, and S. Baumgärtner. 2011. The relationship between resilience and sustainability of ecologicaleconomic systems. Ecological Economics 70(6):1121-1128. http:// dx.doi.org/10.1016/j.ecolecon.2011.01.003

Ding, D., D. Bennett, and S. Secchi. 2015. Investigating impacts of alternative crop market scenarios on land use change with an agent-based model. Land 4(4):1110-1137. http://dx.doi. org/10.3390/land4041110

Elmqvist, T., C. Folke, M. Nystrom, G. Peterson J. Bengtsson, B. Walker, and J. Norberg. 2003. Response diversity, ecosystem change, and resilience. Frontiers in Ecology and the Environment 1(9):488-494. http://dx.doi.org/10.1890/1540-9295(2003)001[0488: rdecar]2.0.co:2

Fischer, J., T. A. Gardner, E. M. Bennett, P. Balvanera, R. Biggs, S. Carpenter, T. Daw, C. Folke, R. Hill, T. P. Hughes, T. Luthe, M. Maass, M. Meacham, A. V Norström, G. Peterson, C. Queiroz, R. Seppelt, M. Spierenburg, and J. Tenhunen. 2015. Advancing sustainability through mainstreaming a socialecological systems perspective. Current Opinion in Environmental Sustainability 14:144-149. http://dx.doi.org/10.1016/j.cosust.2015.06.002

Fletcher, M.-S., S. W. Wood, and S. G. Haberle. 2014. A fire-driven shift from forest to non-forest: evidence for alternative stable states? Ecology 95(9):2504-2513. http://dx.doi.org/10.1890/12-1766.1

Foley, J., N. Ramankutty, K. Brauman, E. S. Cassidy, J. S. Gerber, M. Johnston, N. D. Mueller, C. O'Connell, D. K. Ray, P. C. West, C. Balzer, E. M. Bennett, S. R. Carpenter, J. Hill, C. Monfreda, S. Polasky, J. Rockström, J. Sheehan, S. Siebert, D. Tilman, and D. P. M. Zaks. 2011. Solutions for a cultivated planet. Nature 478:337-342. http://dx.doi.org/10.1038/nature10452

Folke, C. 2006. Resilience: the emergence of a perspective for social-ecological systems analyses. Global Environmental Change 16(3):253-267. http://dx.doi.org/10.1016/j.gloenvcha.2006.04.002

Folke, C., S. Carpenter, T. Elmqvist, L. Gunderson, C. S. Holling, and B. Walker. 2002. Resilience and sustainable development: building adaptive capacity in a world of transformations. $A M B I O$ 31(5):437-440. http://dx.doi.org/10.1579/0044-7447-31.5.437

Folke, C., S. Carpenter, B. Walker, M. Scheffer, T. Elmqvist, L. Gunderson, and C. S. Holling. 2004. Regime shifts, resilience, and biodiversity in ecosystem management. Annual Review of Ecology, Evolution, and Systematics 35:557-581. http://dx.doi. org/10.1146/annurev.ecolsys.35.021103.105711

Gordon, R. J. 2012. Is U.S. economic growth over? Faltering innovation confronts the six headwinds. NBER Working Paper No. 18315, National Bureau of Economic Research. http://dx. doi.org/10.3386/w18315

Gray, S. A., S. Gray, J. L. De Kok, A. E. R. Helfgott, B. O’Dwyer, R. Jordan, and A. Nyaki. 2015. Using fuzzy cognitive mapping as a participatory approach to analyze change, preferred states, and perceived resilience of social-ecological systems. Ecology and Society 20(2):11. http://dx.doi.org/10.5751/es-07396-200211

Grimm, V., U. Berger, D. L. DeAngelis, J. G. Polhill, J. Giske, and S. F. Railsback. 2010. The ODD protocol: a review and first update. Ecological Modelling 221(23):2760-2768. http://dx.doi. org/10.1016/j.ecolmodel.2010.08.019

Gunderson, L. H. 2000. Ecological resilience - in theory and application. Annual Review of Ecology and Systematics 31(1):425439. http://dx.doi.org/10.1146/annurev.ecolsys.31.1.425

Gunderson, L. H., S. Carpenter, C. Folke, P. Olsson, and G. Peterson. 2006. Water RATs (resilience, adaptability, and 
transformability) in lake and wetland social-ecological systems. Ecology and Society 11(1):16. [online] URL: http://www. ecologyandsociety.org/vol11/iss1/art16/

Gunderson, L. H., and C. S. Holling, editors. 2002. Panarchy: understanding transformation in human and natural systems. Island Press, Washington, D.C., USA.

Holling, C. S. 1973. Resilience and stability of ecological systems. Annual Review of Ecology and Systematics 4(1):1-23. http://dx. doi.org/10.1146/annurev.es.04.110173.000245

Holling, C. S. 2001. Understanding the complexity of economic, ecological, and social systems. Ecosystems 4(5):390-405. http:// dx.doi.org/10.1007/s10021-001-0101-5

Iowa State University Extension and Outreach (ISU). $2015 a$. Cash rental rates for Iowa 2015 survey. [online] URL: https://store. extension.iastate.edu/Product/fm1851-pdf

Iowa State University Extension and Outreach (ISU). $2015 b$. Estimated costs of crop production in Iowa - 2015. [online] URL: https://www.extension.iastate.edu/agdm/crops/pdf/a1-20 2015.pdf

Ives, A. R., and S. R. Carpenter. 2007. Stability and diversity of ecosystems. Science 317 (5834):58-62. http://dx.doi.org/10.1126/ science. 1133258

Janssen, M. A. 2010. Population aggregation in ancient arid environments. Ecology and Society 15(2):19. [online] URL: http:// www.ecologyandsociety.org/vol15/iss2/art19/

Janssen, M. A., Ö. Bodin, J. M. Anderies, T. Elmqvist, H. Ernstson, R. R. J. Mcallister, P. Olsson, and P. Ryan. 2006. Toward a network perspective of the study of resilience in socialecological systems. Ecology and Society 11(1):15. [online] URL: http://www.ecologyandsociety.org/vol11/iss1/art15/

Janssen, M., and S. Carpenter. 1999. Managing the resilience of lakes: a multi-agent modeling approach. Conservation Ecology 3 (2):1-26.

Kates, R. W., W. C. Clark, R. Correll, J. M. Hall, C. C. Jaeger, I. Lowe, J. J. McCarthy, H. J. Schellnhuber, B. Bolin, N. M. Dickson, S. Faucheaux, G. C. Gallopin, A. Grübler, B. Huntley, J. Jäger, N. S. Jodha, R. E. Kasperon, A. Mabogunje, P. Matson, H. Mooney, B. Moore III, T. O'Riordan, and U. Svedin. 2001. Sustainability science. Science 292(5517):641-642. http://dx.doi. org/10.1126/science. 1059386

Kinzig, A., P. Ryan, M. Etienne, H. Allison, T. Elmqvist, and B. Walker. 2006. Resilience and regime shifts: assessing cascading effects. Ecology and Society 11(1):20. [online] URL: http://www. ecologyandsociety.org/vol11/iss1/art20/

Lam, N. S.-N., Y. Qiang, H. Arenas, P. Brito, and K.-B. Liu. 2015. Mapping and assessing coastal resilience in the Caribbean region. Cartography and Geographic Information Science 42(4):315-322. http://dx.doi.org/10.1080/15230406.2015.1040999

Lewontin, R. C. 1969. Meaning of stability. Brookhaven Symposia In Biology:13.

Malanson, G. P., Y. Zeng, and S. J. Walsh. 2006. Landscape frontiers, geography frontiers: lessons to be learned. Professional Geographer 58(4):383-396. http://dx.doi.org/10.1111/

j.1467-9272.2006.00576.x
Manson, S. M. 2001. Simplifying complexity: a review of complexity theory. Geoforum 32(3):405-414. http://dx.doi. org/10.1016/s0016-7185(00)00035-X

May, R. 1977. Thresholds and breakpoints in ecosystems with a multiplicity of stable states. Nature 269(5628):471-477. http://dx. doi.org/10.1038/269471a0

McLeman, R., and B. Smit. 2006. Vulnerability to climate change hazards and risks: crop and flood insurance. Canadian Geographer 50(2):217-226. http://dx.doi.org/10.1111/ j.0008-3658.2006.00136.X

Meadows, D. H., D. L. Meadows, J. Randers, and W. W. Behrens. 1972. The limits to growth. Universe Books, New York, USA.

Menck, P. J., J. Heitzig, N. Marwan, and J. Kurths. 2013. How basin stability complements the linear-stability paradigm. Nature Physics 9(2):89-92. http://dx.doi.org/10.1038/nphys2516

Morecroft, M. D., H. Q. P. Crick, S. J. Duffield, and N. A. Macgregor. 2012. Resilience to climate change: translating principles into practice. Journal of Applied Ecology 49:547-551. http://dx.doi.org/10.1111/j.1365-2664.2012.02136.x

Muste, M. V., D. A. Bennett, S. Secchi, J. L. Schnoor, A. Kusiak, N. J. Arnold, S. K. Mishra, D. Ding, and U. Rapolu. 2013. Endto-end cyberinfrastructure for decision-making support in watershed management. Journal of Water Resources Planning and Management 139(5):565-573. http://dx.doi.org/10.1061/(asce) wr.1943-5452.0000289

Nassauer, J. I., J. A. Dowdell, Z. Wang, D. McKahn, B. Chilcott, C. L. Kling, and S. Secchi. 2010. Iowa farmers' responses to transformative scenarios for Corn Belt agriculture. Journal of Soil and Water Conservation 66 (1):18A-24A. http://dx.doi. org/10.2489/jswc.66.1.18a

Nelson, R. G., J. C. Ascough II, and M. R. Langemeier. 2006. Environmental and economic analysis of switchgrass production for water quality improvement in northeast Kansas. Journal of Environmental Management 79 (4):336-347. http://dx.doi. org/10.1016/j.jenvman.2005.07.013

Noble, I. R., S. Huq, Y. A. Anokhin, J. Carmin, D. Goudou, F. P. Lansigan, B. Osman-Elasha, and A. Villamizar. 2014. Adaptation needs and options. Pages 833-868 in C. B. Field, V. R. Barros, D. J. Dokken, K. J. Mach, M. D. Mastrandrea, T. E. Bilir, M. Chatterjee, K. L. Ebi, Y. O. Estrada, R. C. Genova, B. Girma, E. S. Kissel, A. N. Levy, S. MacCracken, P. R. Mastrandrea, and L. L. White, editors. Climate change 2014: impacts, adaptation, and vulnerability. Part A: global and sectoral aspects. Contribution of Working Group II to the Fifth Assessment Report of the Intergovernmental Panel on Climate Change. Cambridge University Press, New York, New York, USA.

Papanicolaou, A. N. (T.)., K. M. Wacha, B. K. Abban, C. G. Wilson, J. L. Hatfield, C. O. Stanier, and T. R. Filley. 2015. From soilscapes to landscapes: a landscape-oriented approach to simulate soil organic carbon dynamics in intensively managed landscapes. Journal of Geophysical Research Biogeosciences (120):2375-2401. http://dx.doi.org/10.1002/2015jg003078 
Parker, D. C., S. M. Manson, M. A. Janssen, M. J. Hoffmann, and P. Deadman. 2003. Multi-agent systems for the simulation of land-use and land-cover change: a review. Annals of the Association of American Geographers 93(2):314-337. http://dx. doi.org/10.1111/1467-8306.9302004

Peterson, G. 2002. Estimating resilience across landscapes. Conservation Ecology 6(1):1-11.

Peterson, G., C. R. Allen, and C. S. Holling. 1998. Ecological resilience, biodiversity, and scale. Ecosystems 1(1):6-18. http://dx. doi.org/10.1007/s100219900002

Pielou, E. C. 1975. Ecological diversity. Wiley-Interscience, New York, USA.

R Core Team. 2015. R: a language and environment for statistical computing. R Foundation for Statistical Computing, Vienna, Austria. [online] URL: https://www.R-project.org/

Rabalais, N. N., R. E. Turner, and W. J. Wiseman, Jr. 2002. Gulf of Mexico hypoxia, a.k.a. "The dead zone." Annual Review of Ecology and Systematics 33(1):235-263. http://dx.doi. org/10.1146/annurev.ecolsys.33.010802.150513

Renard, K. G., G. R. Foster, G. A. Weesies, and J. P. Porter. 1991. RUSLE: revised universal soil loss equation. Journal of Soil and Water Conservation 46(1):30-33.

Rinaldi, S., and M. Scheffer. 2000. Geometric analysis of ecological models with slow and fast processes. Ecosystems 3 (6):507-521. http://dx.doi.org/10.1007/s100210000045

Scheffer, M., J. Bascompte, W. A. Brock, V. Brovkin, S. R. Carpenter, V. Dakos, H. Held, E. H. van Nes, M. Rietkerk, and G. Sugihara. 2009. Early-warning signals for critical transitions. Nature 461(7260):53-59. http://dx.doi.org/10.1038/nature08227

Scheffer, M., S. Carpenter, J. A. Foley, C. Folke, and B. Walker. 2001. Catastrophic shifts in ecosystems. Nature 413(6856):591596. http://dx.doi.org/10.1038/35098000

Schilling, K., M. Streeter, K. Hutchinson, C. Wilson, B. Abban, K. Wacha, and A. Papanicolaou. 2015. Effects of land cover on streamflow variability in a small Iowa watershed: assessing future vulnerabilities. American Journal of Environmental Sciences 11 (4):186-198. http://dx.doi.org/10.3844/ajessp.2015.186.198

Schnoor, J. L. 2012. The U.S. drought of 2012. Environmental Science \& Technology 46(19):10480-10480. http://dx.doi. org/10.1021/es303416z

Turner, B. L. II, R. E. Kasperson, P. A. Matson, J. J. McCarthy, R. W. Corell, L. Christensen, N. Eckley, J. X. Kasperson, A. Luers, M. L. Martello, C. Polsky, A. Pulsipher, and A. Schiller. 2003. A framework for vulnerability analysis in sustainability science. Proceedings of the National Academy of Sciences of the United States of America 100(14):8074-8079. http://dx.doi.org/10.1073/ pnas. 1231335100

United States Department of Agriculture (USDA). 2013. Web soil survey. Natural Resources Conservation Service. [online] URL: http://websoilsurvey.nrcs.usda.gov/

Walker, B., L. H. Gunderson, A. Kinzig, C. Folke, S. Carpenter, and L. Schultz. 2006. A handful of heuristics and some propositions for understanding resilience in social-ecological systems. Ecology and Society 11(1):13. [online] URL: http://www. ecologyandsociety.org/vol11/iss1/art13/

Walker, B., C. S. Holling, S. Carpenter, and A. Kinzig. 2004. Resilience, adaptability and transformability in social-ecological systems. Ecology and Society 9(2):5.

Walker, B., D. Ludwig, C. S. Holling, and R. M. Peterman. 1981. Stability of semi-arid savanna grazing systems. Journal of Ecology 69(2):473-498. http://dx.doi.org/10.2307/2259679

Wu, J. 1999. Crop insurance, acreage decisions, and nonpointsource pollution. American Journal of Agricultural Economics 81 (2):305-320. http://dx.doi.org/10.2307/1244583

Zhou, H., J. Wang, J. Wan, and H. Jia. 2010. Resilience to natural hazards: a geographic perspective. Natural Hazards 53(1):21-41. http://dx.doi.org/10.1007/s11069-009-9407-y 